\title{
Evaluation of an Educational Program on Nurses' Practices for Children with Burns Injuries attending Burns Specialist Hospital in Baghdad City
}

\author{
Ali A. AL-Sudani, $\mathrm{MScN}^{*}$, Eqbal G. Ali, $\mathrm{PhD}^{* *}$ \\ *Supervisor of Nursing, Al- karkh General Hospital, Ministry of Health. \\ ** Professor. Pediatric Nursing, Department, College of Nursing, University of Baghdad.
}

\begin{abstract}
Objective (s): Identify nurses' relationships between nurse's demographic characteristics like (age, gender, level of education, years of experience in burn units, monthly income, course of training in burns) and their practices provided for children with burn injuries attending burns specialist hospital in Baghdad city.

Methodology: A quasi-experimental study design was carried out at burns specialist the non -Teaching Hospital in Baghdad City from June 1th of 2016 up to the 9th of June 2017. Non probability (purposive) sample of (46) nurses were selected from burns wards in non-Teaching Hospital in Baghdad City, and they have at last one year of experience in burn units of the Hospital, they have been taught an educational program related to the care provided to children with burns injuries. The study instruments consisted of two major parts was constructed for the purpose of the study. First part related to nurses" demographic data, the second part related to nurse's practices which composed of (52) items of nurses' practices of child's with burns at burn units. The data were collected through using of constructed questionnaire, which consisted of (52) items and filled by the research using observational checklist after the application of an education competencies related to burns care. Select the stability of the questionnaire carried out through a group of 18 experts, data analyzed through using two statistical approaches: descriptive statistical analysis frequencies and inferential statistical analysis

Results: The study results revealed table shows that the study group nurses' practices at the pre-test is failing, while at the post-test one their practices changed and become acceptable and good practices. Moreover, the findings reflects that the a significant relationship between nurse's practices and their monthly income, training sessions, number of training sessions and place of training sessions. While there is a non-significant relationship between their nurses' practices and the remaining variables like (age, gender, level of education, years of experience in burn units at p-value more than 0.05 .

Recommendation: The staff nurses should be specially trained in these wards based on burns wound care. The periodic workshops and lectures should be conducted by the tutors and physicians for staff nurses General education a topic on "burns wounds care" should be included as a health teaching for burn patient and their relatives. The study recommended that an educational about burns care by providing educational posters ,guidelines, pamphlets and manuals, and training program of burns care. Important for the nurses working in burns wards, developing of follow up child's with burns and the nurses' education level should be improved through an increasing the number of professional nurses employed in burns wards. Intensive care unit, surgical ward, and causality.
\end{abstract}

Keywords: Evaluation, Nurses' Practices, Children, Burns Injuries.

\section{Introduction}

The burns are among the most intensely painful injuries. All patients will experience pain, regardless of the cause, size, or depth of the burn. Wound care is the main source of the pain associated with burn injury despite advances in topical wound care and pharmacology, and a growing emphasis on palliative care. A deeper understanding of many aspects of treating burns and their associated pain can help nurses to provide more effective analgesia (1). .

Rachel (2009) mentioned that a few nursing research has focused on nurse's experiences of nursing services provided to the severe burns injury patient's Which provided a gateway to explore, describe and document the experiences. This thereby adds to the existing body of nursing quality upon which the nursing care of patients with severe injury can be made in an informative manner with confidence (2).

Through these intravenous lines, the patient is quickly given pain or other medications to make them more comfortable, and provide extra fluid so the patient doesn't go in to "shock". Burn injuries cause the body to release chemicals into the good fluid perfusion, so that fluids leak out of the blood vessels and into the lungs and areas around the burn. Over the first few hours, and maybe even days to weeks, this makes the patients look swollen or puffy, and at means that extra fluids must given to keep up with their needs. After several days to 
weeks, this will stop happening, the fluids will go back into the bloodstream (3).

There was a significant number of children admitted with extensive and complex burn injuries to the ward. The balance between the number of available staff, skill mix, care organization and high workload had major influence on safety and efficiency of care delivered to the children, as well as the staff who had to endure the situation. The nurse role was to ensure that the nurses were clinically supported and that education was made available for them to provide effective, efficient and safe care to the children admitted with burns. Some nurses who were not clinically prepared to care for the children with burns had no alternative other than to help with the less complex burn dressing (4)

The dermis is much thicker than the epidermis and it contains blood vessels, nerves, lymph vessels, hair follicles, and sweat glands. It is held together by a protein called collagen. The subcutaneous layer is a connective tissue layer at the base of the skin (5).

Stated that nursing care is provided for people with widely diverse health and sick care needs in multiple contexts worldwide. The knowledge and competence to meet such a wide variety of care needs may be daunting for the student starting a programmer of study to become a registered nurse. Nursing programmers are designed to allow knowledge and practice experience to be accumulated and assimilated by the nursing student within the 3 or 4 year course period. (6).

The positive patient outcomes are dependent on the composition of the burn care team and close collaboration among its members. At the center of this team is the burn nurse, the coordinator of all patient care activities. The complexity and multisystem involvement of the burn patient demand that the burn nurse possess a broad-based knowledge of multisystem organ failure, critical care techniques, diagnostic studies and rehabilitative and psychosocial skills (7).

Therefore, providing safety of burn nursing care to patients is an important, accordance with clinical practice guidelines which is developed by the service. The minimization of infection risk is a priority issue for the service with infection surveillance mechanisms in place. Medical, nursing and allied health staffing levels and expertise are sufficient to maintain safety in the management of burn patients. The service promotes fire safety and burn prevention activities in the community. Optimal first aid management and initial resuscitation of the patient with a severe burn injury are providing (8)

The situation in Iraq published data regarding burns in Iraq including Kurdistan are scarce .The WHO estimates that there were 3, 390 fire-related deaths in 2004 in Iraq which is equivalent to a death rate of 12.3 per 100,000 per year, which is higher than the global rate (9).

Doan (2011) emphasizes that nurses spend more time with their patients each day than any other of the multidisciplinary team members and have the most interactions with the patient and his/her family. They provide the hour to hour care and reinforces repeatedly to the family what the physician has said as well as the plan of care and the course of the care (10).

Therefore highlights Annual death rate from burns in the pediatric population in Colombia was 0.901 per 100,000 . Fire is the principal cause of burn deaths in Colombia, followed by electrical burns. The average annual percent mortality change for burn deaths was $5.17 \%$. Children under 5 years of age account for the highest mortality rates (11).

Administrative arrangement: An official permission is obtained from the Ministry of Planning Central Council of Statistics for the acceptance of the draft of the instrument, Another approval is issued from the Ministry of Health Baghdad city non Teaching Hospital and initial agreement of one non Teaching Hospital in Baghdad city in order to carry out the study and finally subject agreement is also obtained from the nursing staff, in burn units and, him/her self to participant The participant were asked to answer within approximately (30-35) minutes to the questionnaire.

Design of the Study: A quasi-experimental design evaluation of the study is conducted at Baghdad non Teaching Hospital. The study is carried out to determine the nurses practices toward children with burns injuries in burn units from June 1 th 2016 to the 2th June 2017.

Setting of the Study: The study is carried out at Baghdad city non Teaching Hospital. A total of (2) burn units is selected for the purpose of the study. This hospital had included the prince Specialist Burns Hospital were in the AL- Russafa side of Baghdad.

The instruments: Constructional after an extensive review of literature, instruments is constructed for the purpose of study. The researcher according to the burn units and nursing care for child's with burns injuries to measure the underlying concepts in the present study the questionnaire. It is composed of two parts part one for demographic data and the second part overall items, which are included (52) items. All these items have been measured, scored and rated according to liker scale which are indicated by 3 levels score (3) for never (1) score, while (2) score for the sometimes and (3) scores for always.

Data Collection :Data are collected by the researcher collected the subjects' responses through direct observation of their practices technique as means of data collection and keeping records of all available contact that facilitates the access to the study sample. Checklist takes approximately (30 -35) minutes to be checked for 
each nurse. In order to achieve the early stated objectives, the data of the study were analyzed through the use of statistical package of social sciences (SPSS) version 18 through descriptive and inferential statistical analysis.

Table (1): Evaluation of the study Group Nurses' practices (pre-test, post-test one)

\begin{tabular}{|c|c|c|c|c|c|c|}
\hline \multirow{2}{*}{ Items } & \multicolumn{3}{|c|}{ Pre-Test } & \multicolumn{3}{|c|}{ Post-Test One } \\
\hline & M.S & S.D & Evaluation & M.S & S.D & Evaluation \\
\hline Wright done full name of child & 2.70 & 0.47 & Good & 2.96 & 0.21 & Good \\
\hline Wright done causes of injury & 1 & 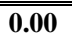 & Poor & 2 & 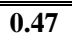 & Good \\
\hline Assess percentage and the degree of burns & 1 & 0.00 & Poor & 2.61 & 0.50 & Good \\
\hline Put done date of admission in the hospital & 2.8 & $\mathbf{0 . 3 9}$ & Good & $\mathbf{3 . 0 0}$ & (2000 & Good \\
\hline Wright done child's age & 2.22 & 0.42 & Poor & 2.91 & 0.29 & Good \\
\hline Wright done child's address & 2.8 & 0.39 & Good & 2.91 & 0.29 & Good \\
\hline Ask about child's past and present medical history & 1 & 0.00 & Poor & 1.48 & 0.51 & Fair \\
\hline Wright done name of physician & 2.7 & 0.47 & Good & $\mathbf{3 . 0 0}$ & 0.00 & Good \\
\hline Preparation of the child's bed & 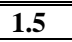 & 0.59 & Poor & 2.43 & 0.51 & Good \\
\hline $\begin{array}{l}\text { Prepare a sterile surgical equipment for changing the } \\
\text { dressing of the patient with burns }\end{array}$ & 1 & 0.00 & Poor & 2.30 & 0.47 & Good \\
\hline $\begin{array}{l}\text { Used disinfection to sterilize the bathroom washing between } \\
\text { patient and another }\end{array}$ & 2.1 & 0.78 & Fair & 2.87 & 0.34 & Fair \\
\hline Check the temperature of water used to wash the burns' & 2.35 & 0.57 & Good & 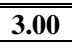 & $\overline{0.00}$ & Good \\
\hline $\begin{array}{l}\text { Used a sterile medical solution (iodine) to sterilize the } \\
\text { affected burns area }\end{array}$ & 2.8 & 0.49 & Good & 2.87 & 0.34 & Good \\
\hline Wearing a head cover & 1 & $\overline{0.00}$ & Poor & 2.78 & $\overline{0.42}$ & Good \\
\hline Used ointments for dressing burn wound & 2.1 & 0.81 & Fair & 2.48 & 0.51 & "Good \\
\hline Wearing a sterile uniform & 1 & 0.00 & Poor & 2.65 & 0.49 & Good \\
\hline Wearing a respiratory face mask & 1.13 & $\overline{0.46}$ & Poor & 2.43 & 0.51 & "Good \\
\hline Wearing a sterile gloves for each patient & 2.17 & $\mathbf{0 . 5 8}$ & Fair & 2.78 & 0.42 & Good \\
\hline Wearing a special shoes (slipper) for burn units & 2.65 & 0.65 & Good & 3.00 & 0.00 & Good \\
\hline $\begin{array}{l}\text { Prepare a sterile dressing materials such as cotton -to wrap } \\
\text { medical gauze and bandages }\end{array}$ & 1.35 & 0.57 & Poor & 2.17 & 0.39 & Fair \\
\hline Wash the affected body burns daily and remove dead tissues & 2.35 & 0.51 & Good & 2.78 & 0.42 & Good \\
\hline Check the skin color & 1.91 & 0.67 & Fair & 2.78 & 0.42 & Good \\
\hline Check the discharge from burn area & 1.78 & 0.74 & Fair & 2.61 & 0.50 & Good \\
\hline Cheek the healing of burn area & 1.70 & 0.76 & Fair & 2.65 & 0.49 & Good \\
\hline $\begin{array}{l}\begin{array}{l}\text { Elevate the affected child limbs to decrease of burn } \\
\text { edema (swelling) as a result of burns injury }\end{array} \\
\end{array}$ & 1.22 & 0.42 & Poor & 2.48 & 0.51 & Good \\
\hline $\begin{array}{l}\text { Monitoring body temperature and recorded in the child } \\
\text { chart }\end{array}$ & 1 & 0.00 & Poor & 2.61 & 0.50 & Good \\
\hline $\begin{array}{l}\text { Monitoring respiration status includes (depth, rate ,sound } \\
\text {,and other abnormalities and recorded in the child chart. }\end{array}$ & 1 & 0.00 & Poor & 2.00 & 0.00 & Fair \\
\hline Monitorino nulse rate and recorded in the child chart. & 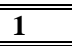 & 0.00 & Poor & 2.30 & 0.47 & Fair \\
\hline Cont.tab .1 $\quad$ cannula of right size & 2.70 & 0.47 & Good & 2.96 & 0.21 & Good \\
\hline Croose a prace rice irom burns to put of the cannula. & 2.52 & 0.51 & Good & $\mathbf{3 . 0 0}$ & (2000 & Good \\
\hline $\begin{array}{l}\text { Checking insertion site of cannula set (hematoma, swelling } \\
\text {,bleeding) and intravenous infusion }\end{array}$ & 1.52 & 0.51 & Poor & 2.17 & 0.39 & Fair \\
\hline Measuring and recording input of fluid in the sheet & 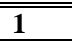 & 0.00 & Poor & 2.70 & 0.47 & Good \\
\hline Measuring and recording of output fluid in the sheet & 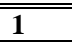 & 0.00 & Poor & 2.78 & $\mathbf{0 . 4 2}$ & Good \\
\hline $\begin{array}{l}\text { Calculate the amount of fluid by the weight and the severity } \\
\text { of burning and the degree of burn }\end{array}$ & 1 & 0.00 & Poor & 2.74 & 0.45 & Good \\
\hline $\begin{array}{l}\text { Observe signs of the inflammation localized to the site of the } \\
\text { cannula }\end{array}$ & 1.65 & 0.49 & Poor & 2.04 & 0.21 & Fair \\
\hline The presence of fluid calculate sheet in the child chart & 2.6 & 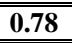 & Good & 2.91 & 0.29 & Good \\
\hline Monitor the $\mathrm{O} 2$ concentration and of infiltration supply & 1.26 & 0.54 & Poor & 2.00 & $\begin{array}{ll}\mathbf{0 . 4 3} \\
\end{array}$ & Fair \\
\hline $\begin{array}{l}\text { Observe of breathing and child response to } \mathrm{O2} \text { therapy } \\
\text { includes (rapid breathing cyanosis and tachycardia) of child. }\end{array}$ & 1.04 & 0.21 & Poor & 2.04 & 0.21 & Fair \\
\hline $\begin{array}{l}\text { Use the stethoscope to check for the amount of air entering } \\
\text { to the child's lungs. }\end{array}$ & 1 & 0.00 & Poor & 2.00 & 0.00 & Fair \\
\hline $\begin{array}{l}\text { document the rate of } \mathrm{O} 2 \text { and the concentration and the time } \\
\text { given } \mathrm{O} 2 \text { in the child chart }\end{array}$ & 1 & 0.00 & Poor & 2.83 & 0.39 & Good \\
\hline Daily weight of the child's & 1 & $\mathbf{0 . 0 0}$ & Poor & 2.17 & 0.39 & Fair \\
\hline Continuously movement of affected Joint( exercise) & 1.74 & 0.62 & Poor & 2.74 & 0.45 & Good \\
\hline Used the (support splint) for affected limbs. & 2.35 & 0.49 & Good & 2.65 & 0.49 & Good \\
\hline Change the child position every two hours. & 1.48 & 0.59 & Poor & 2.96 & 0.21 & "Good \\
\hline Prepare the necessary equipment follies catheter procedure & $\begin{array}{ll}3 \\
\end{array}$ & 0.00 & Good & (3.00 & $\overline{0.00}$ & Good \\
\hline Used disinfection solution for cleaning of genital area at & 2.91 & 0.73 & Good & 2.87 & 0.46 & Good \\
\hline
\end{tabular}




\begin{tabular}{|c|c|c|c|c|c|c|}
\hline procedure & & & & & & \\
\hline Selected appropriate size of catheter at procedure & 1.30 & 0.42 & Poor & 2.91 & 0.29 & Good \\
\hline $\begin{array}{l}\begin{array}{l}\text { Observe signs of the localized inflammation at site of } \\
\text { urinary catheter }\end{array} \\
\end{array}$ & 2.87 & 0.47 & Good & 2.00 & 0.43 & Fair \\
\hline Give the treatment as recorded in the child's chart. & 1.43 & 0.46 & Poor & 2.91 & 0.29 & Good \\
\hline $\begin{array}{l}\text { Send the blood samples to the laboratory for potassium and } \\
\text { calcium checking }\end{array}$ & 1.22 & 0.73 & Poor & 2.35 & 0.49 & Good \\
\hline follow-up results of the tests & 1.83 & 0.52 & Fair & 2.43 & 0.51 & Good \\
\hline 52. Put results of the in the child's chart. & 1.70 & 0.89 & Fair & 2.57 & 0.51 & Good \\
\hline
\end{tabular}

n (23), f (frequency), SD. (standard deviation),good practice (mean equal or more than 2.34), fair practices (mean from $(1.67-2.33)$, poor practice (mean from (1-1.66), cutoff point $(0.66)$.

This table shows that the evaluation of nurses' practices is poor at the pre-test while at the post-test one the evaluation of nurses' practices is good.

Table (2): Correlation between study group post-test knowledge and practices and their demographic data

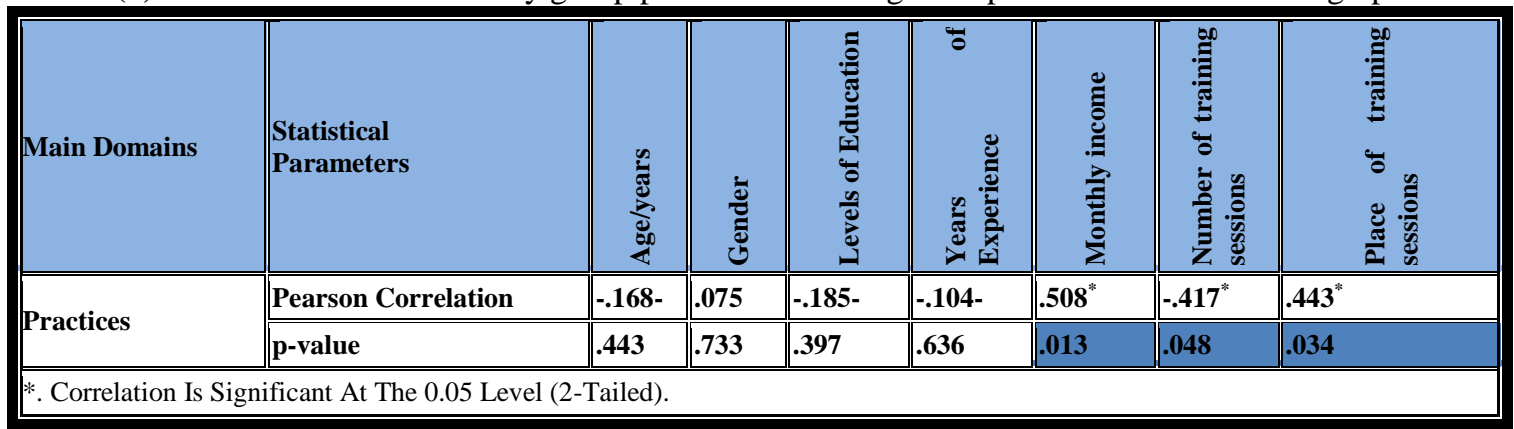

*Significant p-value less than 0.05

This table shows that there is a significant relationship between the nurses' practices and their monthly income, number of training sessions, and place of training sessions at p-value 0.05 .

Table (3) Overall evaluation of study Group Nurses' practices (pre-test, post-test one)

\begin{tabular}{|c|c|c|c|c|c|c|c|c|c|}
\hline \multirow{6}{*}{$\begin{array}{l}\text { Overall Nurses' } \\
\text { Practice }\end{array}$} & \multirow{2}{*}{$\begin{array}{l}\text { Levels of } \\
\text { nurses' } \\
\text { practices }\end{array}$} & \multicolumn{4}{|c|}{ Pre-Test } & \multicolumn{4}{|c|}{ Post-Test One } \\
\hline & & $\mathbf{F}$ & $\%$ & Mean & Evaluation & $\mathbf{F}$ & $\%$ & Mean & Evaluation \\
\hline & Good & $\overline{0}$ & $\overline{\overline{0}}$ & \multirow{4}{*}{1.73} & \multirow{4}{*}{$\begin{array}{l}\text { Poor } \\
\text { Practice }\end{array}$} & 23 & 100 & \multirow{4}{*}{2.60} & \multirow{4}{*}{$\begin{array}{l}\text { Good } \\
\text { practices }\end{array}$} \\
\hline & Poor & $\begin{array}{l}4 \\
\end{array}$ & $\overline{17.4}$ & & & $\overline{\mathbf{0}}$ & $\overline{0}$ & & \\
\hline & Fair & $\overline{\mid 19}$ & $\overline{82.6}$ & & & $\overline{\overline{0}}$ & $\overline{\overline{0}}$ & & \\
\hline & Total & 23 & 100 & & & 23 & $\overline{100}$ & & \\
\hline
\end{tabular}

n23), $f$ (frequency), \% (percentage), good practice (mean equal or more than 2.34), fair practice (mean from 1.67- 2.33), poor practice (mean from 1 - 1.66), cut off point $(0.66)$.

This table shows that the overall evaluation for the study group is poor at pre-test, while at the post test one the overall evaluation is good, that mean there is an effectiveness of the educational program. Discussion of Nursing Practices Scores about Care to the Child's with Burns Injuries.

Concerning the evaluation of an education program on the nurses' practices the results indicated that the nurses' practices concerning nursing some procedures regarding nursing care provided in relation to the admission of children with burns injury at burn units are routine work as information documented like " recorded the full name of child date of admission to the hospital, child's age ,child address, preparation of child's bed ,name of physician etc..." . Therefore, the findings in general indicated that the study sample have a poor practices at pre-test, while at the post-test one the overall evaluation is good (table,3) in regarding registration information of child's admission ,Some procedure regarding nursing care provided in relation to the admission of children with burns injury at burn units are routine work as information documented like " recorded the full name of child date of admission to the hospital, child's age ,child address, preparation of child's bed, name of physician etc..." . Therefore, the findings in general indicated that the sample have a pass and good practices in regarding registration information of child's admission at post-test one (table, 1 and 3 For nursing interventions practices about skin care to the children with burns injury items questionnaire for standard care :" prepare a sterile surgical instruments for changing the dressing of child with burn, disinfection used to sterilize the bathroom washing between one burn child and another, check the temperature of water used to wash the 
burns' child, uses a sterile medical solution (iodine) to sterilize the affected burns' area, used ointment for burns, wearing a face mask, wearing sterile gloves for each patient, wearing a special boot for burn units, prepare sterile dressing materials (cotton ,bandage, and gauze), daily wash the affected body burns and removed death tissues, assessment the burns case of child after the washing process that includes (exudates from burn area, skin color and healing of burn area". These items reflect completed skin care, this is a routine work for nurses to do to child with burn injury. Also this study shows in other items (elevate the affected child's limbs to decreased of swelling, wearing a sterile uniform and wearing a head cover the findings in general indicated that the study sample have a poor practices at pre-test, while at the post-test one the overall evaluation is good (table,1).

Wright et al.,(1992) mention that the interesting note they found that burns nurses in their study experienced low levels of burnout and stress, and high levels of hardiness. Therefore, it is evident that a correlation exists between burnout and hardiness among nurses (11).

The study which found that the majority of staff working in the studied severe burns injury unit, did not experience for burn care. In addition, claimed that burns nurses experience lower levels of depersonalization compared with critical care nurses in which rationale was related to the patient (12).

Clifton et al.,(2015) mention that the requirements of the child's as personal hygiene should be also assessed at this time, as this will assist the nurses in identifying children who should be bathed prior to having applied a new dressing, according to the types of burns and largest of TBSA \% of burns may be dependent on the age (13).

Lyer and Camp (1995) mention that the part of the clinical records information which are written by nurses concerning a patient's health status, nursing needs ,nursing care and response to care .These clinical records facilitate care ,enhance continuity of care, and help coordinate the treatment and evaluation of the patient (14) .

The nurses focused on positive quality for skin care to prevent of infections, joint contracture, scare of skin and another deformities by burn injury. While their dimension of safety remains important of nursing interventions that leads to fewer complications and lower mortality of children with burns injury. Concerning the nurses practices toward follow up of child with burns injury for the following items "check body temperature and recorded in the child's chart ,check respiration status that includes (depth, rate, sound and other abnormalities) and recorded in the child's chart ,check pulse rate and recorded, checking insertion site of the cannula set (hematoma, swelling, bleeding) and intravenous infusion, monitoring and recorded of input fluid, monitoring and recorded output of fluid, calculate the amount of fluid by the child's weight, severity of burn and degree of burns, observe signs of the localize inflammation the site of cannula ,presence of calculate sheet , observe of child's breathing and his or her responses to (O2) includes (rapid of breathing cyanosis and tachycardia), use the stethoscope to check of amount of air entering to the child's lung, document the rate and concentration of $\mathrm{O} 2$ and the time of given (O2) in child's chart, daily child's weight ,continuously movement of affected joint of the lower and upper limbs, working splint for affected limbs, observe signs of the localized inflammation at site of child's indwelling catheter, give the treatment as recorded in the child's chart, send blood samples to the laboratory for potassium and calcium checking, changes the child's position every two hours and follow-up results of the tests and save these results in the child's chart"(table,1).

The results disagree with the finding of the study conducted by (Issac,2006) the findings of the study indicated that professional integrity on and having knowledge of burn management caring for children and the nurses and the hospital appointed specialists have a common understanding of what their role entails and the skills required to provide quality care and support to the children at burn units.(16).

While Dutra et al., (2011) mention that the low percentage of nursing practices and requisite of the knowledge concerning the guidelines for satisfactory initial care of burns patients (17).

Santos, (2009) who shows no significant different between nurses who had a greater affinity for the initial care required by nurses knowledge for patients with burns injuries and demonstrated a higher percentage of satisfactory (18)

Issac, (2006) mention that the most burn wounds are initially sterile. Careful aseptic wound-care procedures along with the use of antimicrobial cream for the first three days are generally sufficient to prevent infection. The wound should be regularly monitored, as infection can delay healing, increase scarring and potentially cause systemic infection (16).

All these items revealed practices which means poor of care provided to child with burns injury at pretest .These results need an important gain steps to improve the care which help in healing charges of child out of the hospital without any complications and to reduce child's mortality and morbidity rate of the child with burns injuries This result of the study indicated the most of nurses have poor practices toward follow up of child with burns injuries. In Relation to Nurse's Demographic Characteristic and Significant Association with Practices for Care of Child's with Burns Injury. The study resultsshows that there is no significant association between nurses age and their practices. The present results of the study agree with result done (14) which indicated that there were no significant difference between nurses' age and their practices (table 2). 
The present results of the study result show that there is a significant association between monthly income and nurses' practices (tale,2). The present results of the study show that there is no significant association between nurses' practices and gender (table,2) this result agreed with (15) obtained from study by which indicated that, there is no relationship between gender and nurses' practices. The present results of the study disagree with result done by (16) their study show no statistical significant association between nurses practices and at their monthly income (table, 2). The finding indicated that there was a significant association between nurses' knowledge and number of training sessions (table, 2). This result was supported by study which revealed no statistical significant association between nurses practices and number of training sessions. The researcher reported that this may be result which lack in planning of training sessions to achieve the Ministry of Health goals (17). The finding indicated that there was no significant association between nurses' practices and their years of experience (table,2) supported this results. There finding show difference in practices, between staff members with difference level of experience, qualification and seniority (18). The finding indicated that there was a significant association between nurses' practices and place of training sessions (table 2). This result might be due to the sufficient training sessions related to nurses' practices toward child with burns injury at burn units with the training inside or outside Iraq. The researcher reported that all nurses' working in burn units learning from each to other, there is no guide or international program to support their practices and help them to improve them and their nursing care provided to the children. . The finding of the study show there was no statistical significant association with level education and nurses' practices about child's with burns since higher percentage of nurse's practices was found among nurses primary school graduate (table 2). These results are in line with this study revealed that positive relationship between nurses' practices and their level of education (4). The present result results of the study disagreed with study who showed that there is relationship between nurse's practices and level of education (19). The present results of the study disagreed with (Mank and Lelie, 2003) who reported that there is relationship between nurse's practices and their level of education.

The present results of the study disagree with obtain from study by their study although is widely used for the prevention of infection of superficial and mild dermal burns, there is currently little evidence supporting its use .The evidence is inconsistent and of limited quality. One un blinded. Study found that there was a wider variety of bacterial flora and a larger amount of bacterial growth with the use of a silicone mesh dressing compared with used a sterile technique according to nurses knowledge for this types of injuries. However, this study found no differences in the signs of infection or the amount of wound drainage in both groups. Another study comparing the same products also found no significant difference in the number of infection (20).

\section{Conclusions}

1. Most of the study sample graduated medical technology institute graduate.

2. Most of the study sample of the study group was (1 10) years of experience of nurses at burns units.

3. Most of the study sample had (2) training sessions of burns care.

4. Most of the study sample participated in training sessions outside Iraq.

5. There was statistical significant association between nurses' practices and their monthly income, place of sessions and number of training sessions.

6. There was no statistical significant association between nurses' practices and their general information.

7. The evaluation of nurses' knowledge and practices is poor at the pre-test while at the post-test one and posttest two the evaluation of nurses practices got good scores nurses toward child with burns injury.

8. Evaluation of overall for the study group practices show is poor and low grade scores at the pre-test while at the post-test one the overall evaluations is good that mean there is an effectiveness of the educational program toward nurses practices for children with burns Injury.

\section{Recommendation}

1-Nursing administration: periodic refreshers courses like an in-service education program should be conducted by the hospitals for the staff nurses.

2-Intensive care unit, surgical ward, and causality: The staff nurses should be specially trained in these wards based on burns wound care. The periodic workshops and lectures should be conducted by the tutors and physicians for staff nurses.

3-General education a topic on "burns wounds care" should be included as a health teaching for burn patient and their relatives.

4-Nursing research: the ultimate goal of any profession is to provide its clients with maximum, effective and efficient services. A profession seeking to improve the practice of its the members and to enhance its professional stature, strives for the continual development of a relevant body of knowledge. The nurses need to engage in multidisciplinary research so that it will help to improve the knowledge and by applying of the health problems can be solved. The need of the patients with burns has to be explored to prepare effective teaching methods thereby contributing to effective and quality nursing care. 
5-Nursing practice learning is an active goal directed process transforming knowledge skills and values into new behavior. Nurses should carefully assess the learners, set the teaching environment, develop good rapport and communication and maintain appropriate documentation. All nurses can work as a school health nurse to increase the communication.

6. It is necessary to establish burns care specialty for the graduates from Nursing College and Medical Technology Institutes.

7. Weekly schedule for films and other available media, continuous education to be presented to the nurses about burn care for children to improve their practices

8. Policy should be initiated to proving a special educational sessions for burns care units nurses'.

9. Improving financial status of nurses' who are working on the burns care units to encourage them.

\section{References}

[1] Patricia, A., Connor - Ballard, PhD.; American of Nursing Journ Understanding and Managing Burn Pain ,2009,Vol. 109, No.4, P.P.48-56..

[2] Foundation Burns and Trauma, Arizona Burn Center ,2004, Available from www.azburn center. Access 21.12.2011

[3] Tortora, Gerard, J.; Principles of Human Anatomy,9th ed., John Wiley and Sons, Inc., Toronto, 2002 .P.P.32.

[4] Dorthy. A qualitative descriptive study of nurses' and hospital play specialists' experiences on a children's burn ward ,Unpublished thesis , Auckland University of Technology, New Zealand ,2006.

[5] Perry, RJ., Moore , CA., Morgan, BD.: Plummer DL."Determining the approximate area of a burn: an inconsistency investigated and re evaluated". 1996, BMJ 312 (7042):P. 1338.

[6] Schultz, GS.: Barillo, DJ., Mozingo, DW.: et al. Wound bed preparation and a brief history of Time, Int .Wound, J. 2004,Vol.9, No.1,P.P. 19-32.

[7] Greenfield, D. and Hungler, B.: Nursing Research:: Principle and Method, 6th ed.; Philadelphia: Lippincott Company, 1999, P.P.416- 417 .

[8] Issac, Dorthy. A qualitative descriptive study of nurses' and hospital play specialists' experiences on a.Children's burn ward ,Unpublished thesis , Auckland University of Technology, New Zealand..2006

[9] Doan and Hall The Ohio State University Medical Center, 410 W. 10th Avenue, N748 Doan H, Columbus, OH. , USA Date of web 12-sep-publication 2011, P. 3.

[10] World Health Organization (WHO): Management of Burns in Children, CPR ., 2004,P.P.3.4

[11] He Robert, Wood, Michelle, Larkin, RN., JD.: Charting Nursing Future, Improving Retention of Older and Experienced Nurses in the Workforce ,2008,P.6.

[12] imbach ,D., Engrav ,L. , and Gibran ,N., Burn Pearls. Seattle, WA: University of Washington Burn Center at Harborvie Medical Center,2003,P.329-334.

[13] Clifton, L., Chong, L. \& Stewart, K.). Identification of factors that predict outpatient utilisation of a plastic dressing clinic. A retrospective review of 287 pediatric burn cases. Burns, $(2015,41,469-475$.

[14] Smith, MA.; Munster, MA. Spence RJ,; Burns of the hand and upper limb, A review Burns ,1998, Vol.24, P.P.493-505.

[15] Hassan,M..: University of Kufa / College of Nursing /Department of Pediatric Nursing Assessment of Pediatric Nurses' Burnout in Al-Najaf Al-Ashraf City, 2015.

[16] Issac, Dorthy. A qualitative descriptive study of nurses' and hospital play specialists' experiences on a children's burn ward ,Unpublished thesis, Auckland University of Technology, New Zealand ,2006.

[17] Dutra AS, Penna LHG, Vargens OMC, Serra MCV. Caracterização de mulheres hospitalizadas por queimaduras. Rev Enferm UERJ. 2011; 19(1):34-9.

[18] Santos SMS, Oliveira MLF. Knowledge about aids and drugs among undergraduate students in a higher education institution in the state of Paraná. Rev Latino-am Enfermagem. 2009; 17(4):

[19] Halfen,R.,Clark,M.,Langer,G.,Jackson,P.; Evaluation of the dissemination and implementation of nutritional guideline for pressure ulcer care ,Journal of wound care,vol.16, Iss,5,2007.P.P.201-205 20-20- Edwards,Jones, V., Green ,wood, JE., What's new in burn microbiology: James Laing memorial prize essay. Burns 2003,Vol.29No.1,P.P.15-24

Ali A. AL-Sudani. "Evaluation of an Educational Program on Nurses' Practices for Children with Burns Injuries attending Burns Specialist Hospital in Baghdad City." IOSR Journal of Nursing and Health Science (IOSR-JNHS) 6.4 (2017): 57-63. 